\title{
Midline episiotomy and anal incontinence: retrospective cohort study
}

\author{
Lisa B Signorello, Bernard L Harlow, Amy K Chekos, John T Repke
}

Obstetrics and
Gynecology
Epidemiology
Center, Brigham
and Women's
Hospital, Harvard
Medical School,
221 Longwood
Avenue, Boston,
MA 02115,
United States
Lisa B Signorello
study coordinator
Bernard L Harlow
associate professor of
obstetrics, gynaecology,
and reproductive
biology
Amy K Chekos
research associate
Department of
Obstetrics and
Gynecology,
Brigham and
Women's Hospital,
Harvard Medical
School, 75 Francis
Street, Boston,
MA 02115,
United States
John T Repke
associate professor of
obstetrics, gynaecology,
and reproductive
biology
Correspondence to:
L B Signorello,
International
Epidemiology
Institute,
1450 Research
Boulevard,
Suite 550, Rockville,
MD 20850,
United States
lbsignore@aol.com

BMJ 2000;320:86-90

\begin{abstract}
Objective To evaluate the relation between midline episiotomy and postpartum anal incontinence. Design Retrospective cohort study with three study arms and six months of follow up.

Setting University teaching hospital.

Participants Primiparous women who vaginally delivered a live full term, singleton baby between 1 August 1996 and 8 February 1997: 209 who received an episiotomy; 206 who did not receive an episiotomy but experienced a second, third, or fourth degree spontaneous perineal laceration; and 211 who experienced either no laceration or a first degree perineal laceration.

Main outcome measures Self reported faecal and flatus incontinence at three and six months postpartum.

Results Women who had episiotomies had a higher risk of faecal incontinence at three (odds ratio 5.5, $95 \%$ confidence interval 1.8 to 16.2$)$ and six (3.7, 0.9 to 15.6) months postpartum compared with women with an intact perineum. Compared with women with a spontaneous laceration, episiotomy tripled the risk of faecal incontinence at three months $(95 \%$ confidence interval 1.3 to 7.9$)$ and six months ( 0.7 to 11.2) postpartum, and doubled the risk of flatus incontinence at three months (1.3 to 3.4) and six months (1.2 to 3.7) postpartum. A non-extending episiotomy (that is, second degree surgical incision) tripled the risk of faecal incontinence (1.1 to 9.0) and nearly doubled the risk of flatus incontinence (1.0 to 3.0) at three months postpartum compared with women who had a second degree spontaneous tear. The effect of episiotomy was independent of maternal age, infant birth weight, duration of second stage of labour, use of obstetric instrumentation during delivery, and complications of labour.

Conclusions Midline episiotomy is not effective in protecting the perineum and sphincters during childbirth and may impair anal continence.
\end{abstract}

\section{Introduction}

Postpartum faecal and flatus incontinence (anal incontinence) is a potentially debilitating condition, the incidence of which has been grossly underappreciated, mainly due to the reluctance of women to seek medical attention for this sensitive problem. ${ }^{1-3}$ Recent epidemiological studies have highlighted the fact that anal incontinence after childbirth is not as rare as has been assumed. As many as $6-10 \%$ of all women experience new defecatory symptoms postpartum, ${ }^{4}$ and anywhere between $13 \%$ and 20\% experience loss of control of flatus. ${ }^{5}$ Of women who experience a third or fourth degree perineal laceration during childbirth, 30-50\% have been reported to experience anal incontinence, ${ }^{6-8}$ even several months after childbirth and despite a primary sphincter repair at the time of the injury. More- over, recent studies have shown that anal incontinence often starts in the early puerperium and persists, contrary to the commonly held view that it does not manifest until years after the obstetric event. ${ }^{19}$

To date, small clinical follow up studies have been undertaken to determine the natural course of anal sphincter disruption or symptoms of incontinence $^{781011}$ as well as to identify predictors of these conditions. $^{1212}$ Studies of predictors have largely implicated obstetric instrumentation (forceps ${ }^{2}{ }^{12}$ and vacuum extractors ${ }^{1}$ ), but there is also some evidence that, independent of its association with instrumental deliveries, episiotomy (surgical incision of the perineum) may increase the risk of sphincter injury. ${ }^{2}$ Advocates of routine episiotomy during childbirth claim that it helps to avoid relaxation of the pelvic floor and perineal trauma, typically documented as third and fourth degree perineal lacerations. ${ }^{13}$ Abundant evidence now exists, however, to show that episiotomy does not prevent trauma to the perineum ${ }^{14}$ and that its use is typically associated with a greater risk of high degree perineal tearing. ${ }^{15-18}$

Two questions that remain unresolved are to what extent does the risk of postpartum anal incontinence vary by degree and type of perineal trauma and does episiotomy predispose to postpartum anal incontinence? More specifically, do women who have episiotomies have a different risk of anal incontinence than women allowed to tear spontaneously to the same degree? To examine these issues we designed a retrospective cohort study to estimate the risk of anal incontinence among a large consecutive sample of primiparous women.

\section{Methods}

\section{Participants}

All participants were drawn from a population of primiparous women who had a singleton, vertex, full term ( $>37$ weeks), vaginal delivery at the Brigham and Women's Hospital in Boston between 1 August 1996 and 8 February 1997. From this study base we constructed three cohorts: an "episiotomy group" comprising women who received an episiotomy during childbirth; a "tear group" comprising women who did not receive an episiotomy but who experienced a second, third, or fourth degree spontaneous perineal laceration; and an "intact group" comprising women who did not receive an episiotomy and who experienced either no perineal laceration or a first degree (superficial) spontaneous perineal laceration. Categorisation into one of these three groups was facilitated by computerised labour and delivery records.

\section{Classification of birth trauma}

We classified the degree of tearing according to standard practice definitions: first degree tear-a perineal laceration extending through the vaginal mucosa and 
perineal skin only; second degree tear-laceration extending into the perineal muscles; third degree tear-laceration involving the external anal sphincter; fourth degree tear-laceration affecting both the anal sphincter and the anorectal mucosa. Perineal trauma was recorded in the birth record by the physician or midwife who attended the birth; no one at the delivery was aware of the study at the time of this recording.

\section{Data collection}

On a weekly basis beginning 29 January 1997 we contacted by post all eligible women who would have been six months postpartum during the following week. For women who comprised the tear group and the intact group, this continued until 31 July 1997. For women who comprised the episiotomy group, a large enough sample (predetermined goal of 200 women) was obtained by 30 April 1997, after which time no women who had had episiotomies were included on the mailing list. Each mailing consisted of a letter describing the study, a research consent form, a self administered questionnaire, and a postage paid return envelope. The letter informed potential participants of our aim to determine which types of medical problems occur after the first vaginal delivery but did not disclose that episiotomy was an exposure of interest.

In total, 921 women were sent questionnaires (282 in the episiotomy group, 290 in the tear group, 349 in the intact group); 29 questionnaires were returned by the post office, indicating that the women were no longer present at that address. Of the 892 questionnaires assumed to have been received, 626 were returned $(70 \%)$. This resulted in the following sample sizes: 211 women in the intact group, 206 women in the tear group, and 209 women in the episiotomy group. Of the 209 episiotomies, 205 were midline episiotomies; we have therefore referred to all procedures simply as "episiotomy".

\section{Outcome}

The self administered questionnaire elicited information regarding demographic and anthropometric factors as well as several pregnancy, labour, delivery, and postpartum experiences, including anal incontinence. Participants were asked to recall their experience with faecal and flatus incontinence at three months postpartum and to report on current occurrences of incontinence (six months postpartum). Faecal incontinence and flatus incontinence were defined in the questionnaire as "having a bowel movement" or "passing gas," respectively, "when you don't mean to." We also asked the women to report any history of anal incontinence, allowing us to identify strictly new versus prevalent cases. All data from the questionnaire were subsequently linked to computerised labour and delivery records to incorporate clinical data such as the use of obstetric instrumentation, infant birth weight, duration of the second stage of labour (calculated as the time of birth minus the time at which full cervical dilation was achieved), and complications arising during labour.

\section{Statistical analysis}

Crude risks were calculated as the number of newly incontinent women divided by the number of women with no history of that type of incontinence in each
Table 1 Descriptive characteristics of women and events during delivery. Figures are numbers (percentage) of women unless stated otherwise

\begin{tabular}{|c|c|c|c|}
\hline Characteristic & $\begin{array}{c}\text { Intact/1st degree } \\
\text { tear }(n=211)\end{array}$ & $\begin{array}{c}\text { 2nd/3rd/4th degree } \\
\text { tear }(n=206)\end{array}$ & $\begin{array}{c}\text { Episiotomy } \\
(\mathrm{n}=209)\end{array}$ \\
\hline \multicolumn{4}{|l|}{ Age (completed years): } \\
\hline$<20$ & $25(11.85)$ & $3(1.46)$ & $2(0.96)$ \\
\hline $20-24$ & $36(17.06)$ & $13(6.31)$ & $14(6.70)$ \\
\hline $25-29$ & $56(26.54)$ & $64(31.07)$ & $60(28.71)$ \\
\hline $30-34$ & $67(31.75)$ & $91(44.17)$ & $83(39.71)$ \\
\hline$\geqslant 35$ & $27(12.80)$ & 35 (16.99) & $50(23.92)$ \\
\hline \multicolumn{4}{|l|}{ Weight* $(\mathrm{kg}) \dagger$ : } \\
\hline$<54$ & $43(20.48)$ & 38 (18.72) & $45(22.06)$ \\
\hline $54-61$ & $50(23.81)$ & $66(32.51)$ & $52(25.49)$ \\
\hline $62-70$ & $57(27.14)$ & $58(28.57)$ & $68(33.33)$ \\
\hline$\geqslant 71$ & $60(28.57)$ & $41(20.20)$ & $39(19.12)$ \\
\hline \multicolumn{4}{|l|}{ Height (cm)†: } \\
\hline$<160$ & $38(18.10)$ & $36(17.56)$ & $30(14.42)$ \\
\hline $160-165$ & $65(30.95)$ & $60(29.27)$ & $57(27.40)$ \\
\hline 166-170 & $53(25.24)$ & $63(30.73)$ & $65(31.25)$ \\
\hline$\geqslant 170$ & $54(25.71)$ & $46(22.44)$ & $56(26.92)$ \\
\hline \multicolumn{4}{|l|}{ Ethnic background: } \\
\hline White & 147 (69.67) & $166(80.58)$ & 188 (89.95) \\
\hline African-American & $33(15.64)$ & $6(2.91)$ & $4(1.91)$ \\
\hline Hispanic & $6(2.84)$ & $5(2.43)$ & $2(0.96)$ \\
\hline Asian & $18(8.53)$ & $22(10.68)$ & $10(4.78)$ \\
\hline Other & 7 (3.32) & $7(3.40)$ & $5(2.39)$ \\
\hline \multicolumn{4}{|l|}{ Education: } \\
\hline A level or below & $48(22.75)$ & $21(10.20)$ & $19(9.10)$ \\
\hline Technical college & $15(7.11)$ & $12(5.83)$ & $8(3.83)$ \\
\hline University & $95(45.02)$ & $94(45.63)$ & $103(49.28)$ \\
\hline Postgraduate & $53(25.12)$ & $79(38.35)$ & $79(37.80)$ \\
\hline \multicolumn{4}{|l|}{ Birth weight $(\mathrm{g})$ : } \\
\hline First quartile & 3090 & 3147 & 3204 \\
\hline Median & 3340 & 3374 & 3487 \\
\hline Third quartile & 3617 & 3714 & 3799 \\
\hline \multicolumn{4}{|c|}{ Duration of second stage of labour (minutes): } \\
\hline First quartile & 28 & 48 & 55 \\
\hline Median & 57 & 81 & 109 \\
\hline Third quartile & 103 & 133 & 173 \\
\hline Instrumental delivery & $7(3)$ & $18(9)$ & $56(27)$ \\
\hline Births with complication of labour§ & $37(18)$ & $35(17)$ & $55(26)$ \\
\hline
\end{tabular}

*Weight at six months postpartum.

†Numbers do not always add up to total because of missing data.

‡Forceps or vacuum extractor.

$\S$ Meconium, fetal bradycardia, fetal tachyarrhythmia, deep variable decelerations, pregnancy induced hypertension, chorioamnionitis, rapid rotation and delivery of head, uterine atony, premature rupture of membranes at term, failure to progress, protracted labour, prolonged rupture of membranes, occiput transverse orientation, occiput posterior orientation, protracted descent, macrosomia, mild shoulder dystocia, nuchal cord, placental abruption, retained placenta

group. To calculate relative risks and accommodate simultaneous control of several covariates we used logistic regression to estimate adjusted odds ratios. All analyses were performed with STATA statistical software. For most analyses there were four distinct comparisons of interest: episiotomy group versus intact group, episiotomy group versus tear group, tear group versus intact group, and women with second degree (that is, non-extending) episiotomies versus women with second degree spontaneous perineal tears.

\section{Results}

Table 1 gives descriptive characteristics of the study population. The mean (SD) age of the women in each of the three groups was 28.5 (6.0), 31.2 (4.6), and 31.6 (4.7) years for the intact, tear, and episiotomy groups, respectively. There was little difference in height among the groups, but women in the intact group seemed to be somewhat heavier than the other women. 
Table 2 Risk of anal incontinence three and six months after childbirth for varying degrees of perineal injury. Figures are numbers (percentage) of women

\begin{tabular}{lcccccc} 
Outcome & $\begin{array}{c}\text { Intact/1st degree } \\
\text { tear (intact group) }\end{array}$ & $\begin{array}{c}\text { 2nd degree } \\
\text { tear }\end{array}$ & $\begin{array}{c}\text { 3rd/4th degree } \\
\text { tear }\end{array}$ & $\begin{array}{c}\text { 2nd/3rd/4th degree } \\
\text { tear (tear group) }\end{array}$ & $\begin{array}{c}\text { Episiotomy } \\
\text { (episiotomy group) }\end{array}$ & $\begin{array}{c}\text { Episiotomy with } \\
\text { no extension }\end{array}$ \\
\hline Faecal incontinence: & & & & & & \\
\hline At 3 months & $5 / 205(2.4)$ & $5 / 154(3.3)$ & $2 / 50(4.0)$ & $7 / 204(3.4)$ & $20 / 203(9.9)$ & $13 / 147(8.8)$ \\
\hline At 6 months & $3 / 201(1.5)$ & $3 / 152(2.0)$ & $0 / 49(0)$ & $3 / 201(1.5)$ & $8 / 195(4.1)$ & \\
\hline Flatus incontinence: & & & & & & \\
\hline At 3 months & $40 / 192(20.8)$ & $27 / 144(18.8)$ & $9 / 48(18.8)$ & $36 / 192(18.8)$ & $63 / 187(33.7)$ & $39 / 137(28.5)$ \\
\hline At 6 months & $20 / 188(10.6)$ & $18 / 142(12.7)$ & $5 / 47(10.6)$ & $23 / 189(12.2)$ & $42 / 181(23.2)$ & $26 / 133(19.6)$ \\
\hline
\end{tabular}

The intact group was more ethnically diverse (roughly $30 \%$ non-white) than the tear (20\% non-white) and episiotomy (10\% non-white) groups. The tear and the episiotomy groups were similarly educated and somewhat more so than the intact group.

The average infant birth weight in the episiotomy group was higher than in the tear group $(t$ test $\mathrm{P}=0.01$ ), but birth weight in the tear group was not significantly higher than in the intact group $(\mathrm{P}=0.09)$. We observed that the second stage of labour was shortest for women with an intact perineum and longest for women who underwent an episiotomy. Of births in the episiotomy group, $27 \%$ were aided by instrumentation, either forceps or vacuum extractor, while less than $10 \%$ of births in the other categories involved the use of these instruments. Less than $20 \%$ of births in the intact and tear groups involved a complication of labour compared with one quarter of births in the episiotomy group.

Table 2 presents the overall risk of faecal and flatus incontinence at three and six months postpartum for the three main groups, as well as for subgroups of interest. About $10 \%$ of women with episiotomies were experiencing faecal incontinence three months after giving birth. Women in the tear group and the intact group had less than half that risk. Within the tear group the risk of faecal incontinence was similar for second degree $(3.3 \%)$ versus third or fourth degree laceration $(4.0 \%)$ at three months postpartum. For most groups the prevalence of faecal incontinence at six months postpartum was about half that reported at three months postpartum.

Table 3 Association between postpartum faecal and flatus incontinence and various types of perineal tearing

\begin{tabular}{|c|c|c|}
\hline Outcome and comparison & $\begin{array}{c}\text { Adjusted odds ratio* } \\
(95 \% \mathrm{CI})\end{array}$ & $\begin{array}{l}\text { Restricted odds ratio } \\
(95 \% \mathrm{Cl})\end{array}$ \\
\hline \multicolumn{3}{|l|}{ Faecal incontinence at 3 months } \\
\hline Episiotomy $v$ intact/1st degree tear & 5.5 (1.8 to 16.2$)$ & 6.4 (1.7 to 24.8$)$ \\
\hline Episiotomy $v$ 2nd/3rd/4th degree tear & $3.2(1.3$ to 7.9$)$ & $4.9(1.3$ to 19.0$)$ \\
\hline $2 \mathrm{nd} / 3 \mathrm{rd} / 4$ th degree tear $v$ intact/1st degree tear & $1.4(0.4$ to 5.0$)$ & $1.1(0.2$ to 5.7$)$ \\
\hline \multicolumn{3}{|l|}{ Faecal incontinence at 6 months } \\
\hline Episiotomy $v$ intact/1st degree tear & $3.7(0.9$ to 15.6$)$ & $2.7(0.4$ to 19.0$)$ \\
\hline Episiotomy $v$ 2nd/3rd/4th degree tear & $2.9(0.7$ to 11.2$)$ & $2.2(0.4$ to 13.8$)$ \\
\hline 2 nd/3rd/4th degree tear $v$ intact/1st degree tear & $1.2(0.2$ to 6.4$)$ & $1.2(0.1$ to 9.5$)$ \\
\hline \multicolumn{3}{|l|}{ Flatus incontinence at 3 months } \\
\hline Episiotomy $v$ intact/1st degree tear & $1.7(1.0$ to 2.8$)$ & $1.7(0.9$ to 3.2$)$ \\
\hline Episiotomy $v$ 2nd/3rd/4th degree tear & $2.1(1.3$ to 3.4$)$ & 2.0 (1.1 to 3.6$)$ \\
\hline 2nd/3rd/4th degree tear $v$ intact/1st degree tear & $0.8(0.5$ to 1.4$)$ & $0.9(0.5$ to 1.7$)$ \\
\hline \multicolumn{3}{|l|}{ Flatus incontinence at 6 months } \\
\hline Episiotomy $v$ intact/1st degree tear & $2.3(1.2$ to 4.3$)$ & $3.1(1.4$ to 6.9$)$ \\
\hline Episiotomy $v$ 2nd/3rd/4th degree tear & $2.1(1.2$ to 3.7$)$ & $2.3(1.1$ to 4.8$)$ \\
\hline 2nd/3rd/4th degree tear $v$ intact/1st degree tear & $1.1(0.5$ to 2.1$)$ & $1.2(0.6$ to 2.8$)$ \\
\hline
\end{tabular}

${ }^{*}$ Adjusted for maternal age, infant birth weight, and duration of second stage of labour.

†Analysis restricted to women with no complication of labour and no use of instrumentation (forceps,

vacuum extractor). Adjusted for maternal age, infant birth weight, and duration of second stage of labour.
One third of women in the episiotomy group reported experiencing flatus incontinence at three months postpartum, and nearly one quarter reported this condition at six months postpartum (table 2). In contrast, the prevalence of flatus incontinence among women not receiving episiotomies was about $20 \%$ at three months and $10-13 \%$ at six months postpartum. The prevalence of flatus incontinence at both time periods was similar for all degrees of spontaneous tearing.

After adjustment for maternal age, infant birth weight, and duration of the second stage of labour women who had an episiotomy were more likely to experience anal incontinence than women who did not (table 3). With the exception of faecal incontinence at six months postpartum the risk of all other outcomes was significantly greater among the episiotomy group than among the tear group. Women in the tear group were no more likely to experience anal incontinence than women in the intact group. Further adjustment for body size (by using weight, height, or body mass index), education, and ethnic group did not result in any change to the relative risk estimates.

To eliminate the possibility that use of obstetric instrumentation or other complications of labour were confounding the association between episiotomy and risk of anal incontinence we repeated our analysis in the subset of women who had a spontaneous, non-instrumental birth with no documented complications of labour (table 3). Although with a loss of power, we found that the effect of episiotomy was not influenced by its association with operative or complicated deliveries.

Table 4 shows a comparison of the risk of anal incontinence for the 152 women who had a non-extending episiotomy and the 156 women who had a second degree spontaneous perineal tear. Relative to women with a second degree tear, a non-extending episiotomy tripled the risk of faecal incontinence at three months postpartum and doubled this risk at six months postpartum, although these results were not significant. The risk of flatus incontinence was marginally significantly higher for women with non-extending episiotomies compared with women with second degree tearing. Again, further restriction to uncomplicated births resulted in loss of statistical precision but not in a qualitative or quantitative change in the findings.

\section{Discussion}

Mechanical damage to the external or internal anal sphincter muscles or impairment of innervation to the sphincter, or both, resulting from obstetrical trauma are thought to be the principal causes of anal incontinence in women. ${ }^{2611} 1920$ Sphincter defects acquired 
Table 4 Risk of postpartum anal incontinence among 152 women who had non-extending episiotomies (second degree surgical incisions) compared with 156 women with second degree spontaneous perineal lacerations

\begin{tabular}{lcc} 
Outcome & $\begin{array}{c}\text { Adjusted odds ratio } \\
\text { (95\% Cl) }\end{array}$ & $\begin{array}{c}\text { Restricted odds ratio } \\
\text { (95\% Cl) }\end{array}$ \\
\hline Faecal incontinence: & & \\
\hline At 3 months & $3.1(1.1$ to 9.0$)$ & $3.0(0.7$ to 12.7$)$ \\
\hline At 6 months & $2.4(0.6$ to 9.8$)$ & $2.0(0.3$ to 12.6$)$ \\
\hline Flatus incontinence: & & \\
\hline At 3 months & $1.7(1.0$ to 3.0$)$ & $1.9(0.9$ to 3.8$)$ \\
\hline At 6 months & $1.7(0.9$ to 3.2$)$ & $2.7(1.2$ to 6.1$)$ \\
\hline
\end{tabular}

${ }^{*}$ Adjusted for maternal age, infant birth weight, and duration of second stage of labour.

†Analysis restricted to women with no complication of labour and no use of instrumentation (forceps, vacuum extractor). Odds ratio adjusted for materna age, infant birth weight, and duration of second stage of labour.

during childbirth could be permanent as some investigators have observed no changes in these defects from six weeks to six months postpartum and have noted that the prevalence of occult defects in primiparas after giving birth is the same as the prevalence of defects in multiparas before giving birth. ${ }^{2}$ We did note diminished reporting of symptoms of incontinence over time, though we cannot extend our interpretation beyond six months postpartum.

\section{Episiotomy and sphincter defects}

Overt injury to the sphincter through high degree perineal tearing can occur as a result of a spontaneous laceration or from the extension of an episiotomy and is readily apparent to the clinician. The increasing use of anal endosonography in clinical studies, however, has established that underlying sphincter damage can be present despite the appearance of a normal perineum. ${ }^{20}{ }^{21}$ Our study provides evidence that midline episiotomy increases the risk of postpartum anal incontinence, presumably by causing such occult sphincter trauma. We have shown that, independent of its association with instrumentation, labour complications, high birth weight, and long second stage of labour, midline episiotomy is associated with an increased risk of anal incontinence. Our findings are supported by the work of Sultan et al, who observed that $41 \%(9 / 22)$ of women receiving episiotomies during a noninstrumental delivery had occult sphincter defects detectable on anal endosonography, a proportion higher than that observed for women who did not receive episiotomies. ${ }^{2}$ In the same study, these investigators reported that $35 \%$ of primiparous women had postpartum sphincter damage on endosonography (only 3\% of whom were clinically apparent) and that the internal sphincter was more often damaged than the external sphincter. Thus, although it is obvious that tearing that directly injures the sphincter is likely to compromise its function, attempts to identify predictors of anal incontinence, and thus possible preventive modalities, should look beyond high degree tears.

Our finding that even non-extending midline episiotomies may confer a higher risk of anal incontinence offers evidence that an episiotomy may disrupt innervation or cause mechanical damage to the sphincter to a degree previously unrecognised. One possible explanation derives from the fact that the internal sphincter can be damaged from forces exerted by the infant's head. Because an episiotomy is typically cut before the delivery of the infant's head and a spontaneous tear typically occurs during the emergence of the head or shoulder an episiotomy may allow these forces to be applied closer to the sphincter.

\section{Methodological strengths and limitations}

We cannot rule out misclassification as a possible explanation for our finding concerning non-extending episiotomies as the possibility exists that some of these episiotomies extended to a third degree tear but were not correctly classified by the doctor or midwife. This is an unlikely scenario, however, as a third degree tear is a prominent obstetric event that requires a more complicated repair procedure. In addition, there is little reason to suspect that such misclassification occurred only for episiotomies and not for second degree spontaneous tears.

Misclassification may also provide an explanation for the fact that flatus incontinence, although reported with much higher frequency than faecal incontinence, was less strongly associated with episiotomy. Because all people experience some flatulence, the reporting of flatus incontinence is subject to the judgment of each individual as to whether it truly constitutes incontinence. This type of measurement error, presumably of a non-differential nature, would bias our results towards the null and result in an underestimate of the effect of episiotomy on the risk of flatus incontinence. In contrast, faecal incontinence is an unusual and disturbing event that is undoubtedly reported with greater accuracy.

This study's strengths include the use of consecutive births during a defined time period and data collection after identical follow up for all participants. Also, restriction of the study population to primiparous women eliminated misclassification of exposure that could be introduced by past obstetric injury. High participation rates among the three groups indicate a low chance of selection bias, and our resulting sample size provided adequate power to detect many significant associations, despite the fact that faecal incontinence is an uncommon condition. We also had the opportunity to use accurate, objective, and routinely collected data on important potential confounders such as birth weight, the use of forceps or vacuum extractor, complications, and the duration of the second stage of labour.

The greatest limitation of this study stems from its observational and not intervention driven design. Without randomisation of women to receive an episiotomy or not, it can be challenging to distinguish the effects of episiotomy per se from those caused by factors that provoked the use of episiotomy. During the study period episiotomy was not performed routinely but was performed on the basis of clinical assessment by the provider of obstetric care. It was not performed for the sole indication of an instrumental vaginal delivery, though more liberal criteria were generally applied in these circumstances. We strove to ensure that the labour and deliveries were comparable by restricting sampling (only primiparous women and no breech presentations, multiple births, or premature deliveries), by adjusting for differences in maternal age, infant birth weight, and duration of the second stage of labour, and by performing analyses limited to women with no history of the outcome in question as well as 


\section{What is already known on this subject}

Most anal incontinence in women is thought to arise from injury to the sphincter during childbirth

Operative vaginal deliveries and high degree perineal tears have been implicated in the disruption of sphincter function, but no study to date has been designed specifically to quantify the effect of episiotomy and varying levels of spontaneous perineal trauma on symptoms of anal incontinence

\section{What this study adds}

Midline episiotomy is a risk factor for postpartum anal incontinence, independent of the procedure's association with maternal age, infant birth weight, duration of the second stage of labour, complications of labour, and obstetric instrumentation

Women with appreciable spontaneous perineal tearing are at lower risk of postpartum anal incontinence than women who have midline episiotomies entry, and data cleaning were managed by LBS and AKC. Statistical analyses were performed by LBS and BLH. All authors contributed to the interpretation of the results, as well as to the writing and editing of the manuscript. LBS and BLH are the guarantors for the paper.

Funding: Brigham and Women's Hospital Obstetrics and Gynecology Foundation.

Competing interests: None declared.

1 MacArthur C, Bick DE, Keighley MRB. Faecal incontinence after childbirth. Br J Obstet Gynaecol 1997;104:46-50.

2 Sultan AH, Kamm MA, Hudson CN, Thomas JM, Bartram CI. Anal sphincter disruption during vaginal delivery. N Engl J Med 1993;329: 1905-11.

3 Leigh RJ, Turnberg LA. Faecal incontinence: the unvoiced symptom. Lancet 1982;i:1349-51.

4 Sultan AH, Kamm MA. Faecal incontinence after childbirth. Br J Obstet Gynaecol 1997;104:979-82.

5 Isager-Sally L, Legarth J, Jacobsen B, Bostofte E. Episiotomy repair-immediate and long-term sequelae. A prospective randomised study of three different methods of repair. Br J Obstet Gynaecol 1986;93: $420-5$

6 Sultan AH, Kamm MA, Hudson CN, Bartram CI. Third degree obstetric anal sphincter tears: risk factors and outcome of primary repair. $B M J$ 1994;308:887-91.

7 Nielsen MB, Hauge C, Rasmussen OO, Pedersen JF, Christiansen J. Anal endosonographic findings in the follow-up of primarily sutured sphincteric ruptures. BrJ Surg 1992;79:104-6.

8 Sorensen M, Tetzschner T, Rasmussen OO, Bjarnesen J, Christiansen J Sphincter rupture in childbirth. BrJ Surg 1993;80:392-4.

9 Swash M. Faecal incontinence. Childbirth is responsible for most cases. BMJ 1993;307:636-7.

10 Snooks SJ, Swash M, Mathers SE, Henry MM. Effect of vaginal delivery on the pelvic floor: a 5-year follow-up. Br J Surg 1990;77:1358-60.

11 Deen KI, Kumar D, Williams JG, Olliff J, Keighley MRB. The prevalence of anal sphincter defects in faecal incontinence: a prospective endosonic study. Gut 1993;34:685-8.

12 Sultan AH, Kamm MA, Bartram CI, Hudson CN. Anal sphincter trauma during instrumental delivery. Int J Gynecol Obstet 1993;43:263-70.

13 Thacker SB, Banta HD. Benefits and risks of episiotomy: an interpretive review of the English language literature, 1860-1980. Obstet Gynecol Surv 1983;38:322-38.

14 Thorp JM Jr, Bowes WA Jr. Episiotomy: can its routine use be defended? Am J Obstet Gynecol 1989;160:1027-30.

15 Thorp JM Jr, Bowes WA Jr, Brame RG, Cefalo R. Selected use of midline episiotomy: effect on perineal trauma. Obstet Gynecol 1987;70:260-2.

16 Helwig JT, Thorp JM Jr, Bowes WA Jr. Does midline episiotomy increase the risk of third- and fourth-degree lacerations in operative vaginal deliveries? Obstet Gynecol 1993;82:276-9.

17 Walker MPR, Farine D, Rolbin SH, Ritchie JWK. Epidural anesthesia, episiotomy, and obstetric laceration. Obstet Gynecol 1991;77:668-71.

18 Klein MC, Gauthier RJ, Robbins JM, Kaczorowski J, Jorgensen SH, Franco $\mathrm{ED}$, et al. Relationship of episiotomy to perineal trauma and morbidity, sexual dysfunction, and pelvic floor relaxation. Am J Obstet Gynecol 1994; 171:591-8.

19 Snooks SJ, Swash M, Setchell M, Henry MM. Injury to innervation of pelvic floor sphincter musculature in childbirth. Lancet 1984;2:546-50.

20 Burnett SJD, Spence-Jones C, Speakman CTM, Kamm MA, Hudson CN, Bartram CIB. Unsuspected sphincter damage following childbirth revealed by anal endosonography. Br J Radiol 1991;64:225-7.

21 Frudinger A, Bartram CI, Spencer JAD, Kamm MA. Perineal examination as a predictor of underlying external anal sphincter damage. Br J Obstet Gynaecol 1997;104:1009-13.

(Accepted 1 November 1999)
Epidemiology Unit, London School of Hygiene and Tropical Medicine, London

WC1E 7HT

Anthony Kessel homorary lecturer in public health medicine

continued over

BMJ 2000;320:90-1
In 1989 the Department of Health set up the unlinked anonymous HIV prevalence monitoring programme for England and Wales. ${ }^{1}$ Although support for the programme in the United Kingdom has been generally widespread, concern has been voiced about testing without the individual's explicit consent, and two countries have refused to adopt non-voluntary unlinked anonymous testing programmes for HIV. ${ }^{2}$ We carried out a survey of the public's views on unlinked anonymous testing of blood for HIV and other diseases.

\section{Participants, methods, and results}

Three questions were inserted into the March 1998 Office for National Statistics omnibus survey. Of 3000 addresses selected from the postal address file, 2635 were eligible. Face to face interviews were conducted 